\title{
Cathodoluminescence of aluminum ceramic compounds
}

Cite as: J. Appl. Phys. 125, 025110 (2019); https://doi.org/10.1063/1.5066434

Submitted: 15 October 2018 . Accepted: 22 December 2018 . Published Online: 11 January 2019

Guillaume Demol (D), Thierry Paulmier, and Denis Payan
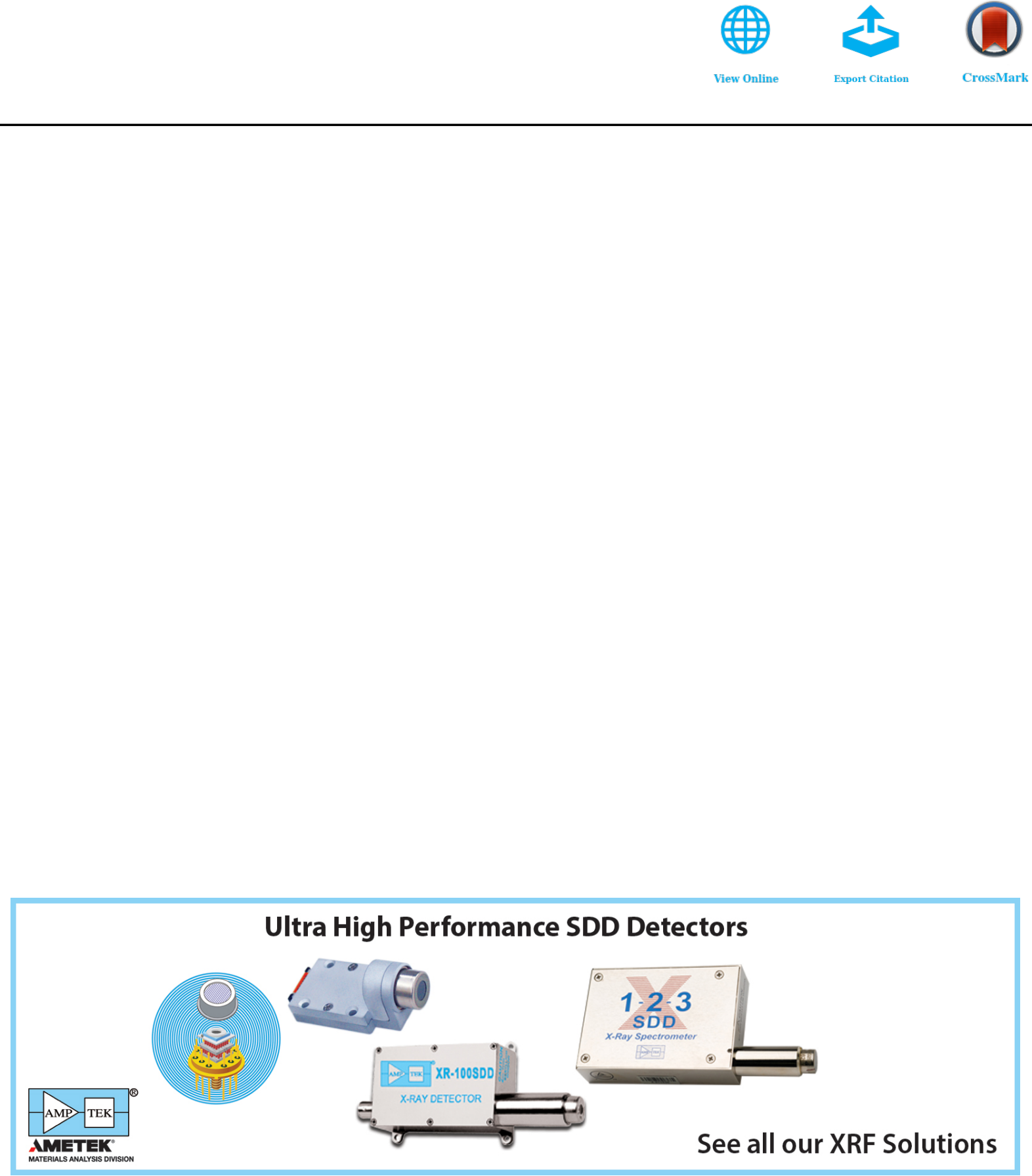


\title{
Cathodoluminescence of aluminum ceramic compounds
}

\author{
Cite as: J. Appl. Phys. 125, 025110 (2019); doi: 10.1063/1.5066434 \\ Submitted: 15 October 2018 . Accepted: 22 December 2018 . \\ Published Online: 11 January 2019
}

Guillaume Demol, ${ }^{1,2}$ (D) Thierry Paulmier, ${ }^{1}$ and Denis Payan ${ }^{2}$

\author{
AFFILIATIONS \\ ${ }^{1}$ ONERA/DPHY, Université de Toulouse, F-31055 Toulouse, France \\ ${ }^{2}$ CNES, The French Space Agency, F-31400 Toulouse, France
}

Electronic addresses: guillaume.demol@onera.fr; thierry.paulmier@onera.fr; and denis.payan@cnes.fr

\begin{abstract}
We compare in this study the differences in cathodoluminescence spectra of aluminum-based materials. $\mathrm{AlN}^{\mathrm{N}}$ and $\mathrm{Al}_{2} \mathrm{O}_{3}$ materials respond differently when subjected to $10 \mathrm{keV}$ charging electron beam. In order to understand the underlying physics, we carried out a parametric study (annealing treatment, temperature, radiation dose, and supplier). Tests have been performed at temperatures ranging from about $150 \mathrm{~K}$ to $300 \mathrm{~K}$, with a monoenergetic electron beam at $10 \mathrm{keV}$, and electron flux density equal to $1 \mu \mathrm{A} \mathrm{cm}^{-2}$. Cathodoluminescence intensity is shown to be highly dependent on temperature, synthesis conditions, thermal annealing treatments, dose, and dose rate. The air-annealing treatment at high temperature increases considerably the concentration of surface defects. We have also been able to demonstrate a significant evolution of cathodoluminescence spectra with the injected radiation dose. These different evolutions have been analyzed in regard to material structure and composition.
\end{abstract}

Published under license by AIP Publishing. https://doi.org/10.1063/1.5066434

\section{INTRODUCTION}

Technical ceramic materials are used for different technological applications. Aluminum-based materials are widely used in light-emitting diodes (LEDs), electronic substrates, and optoelectronics. ${ }^{1,2}$ These types of materials are highly appreciated for their excellent electrical and thermal properties. Due to its high temperature stability, good thermal conductivity, and wide bandgap $\left(\mathrm{E}_{\mathrm{g}} \sim 6.2 \mathrm{eV}\right)$, aluminum nitride is commonly used as an electrical insulator and is a promising source of UV emission (by electron-hole recombination). ${ }^{3-5}$ Aluminum oxide is one of the main ceramic materials used for electrical applications and microelectronics. The gap energy of $\mathrm{Al}_{2} \mathrm{O}_{3}$ is about $9 \mathrm{eV}$.

Ceramics are used in spacecraft for thermal insulation and mechanical support. In space environment, these ceramics are subject to energetic particles that can induce electrical charging (by charge trapping in the ceramic's bulk) of these materials. This charging process can lead to the initiation of electrostatic discharges and electrical arcs. For a better prediction of these charging phenomena, it is necessary to understand the physics steering charge transport and radiation/ceramic interactions.
A specific model has been developed at ONERA taking into account the effects of ionization, trapping, and recombination. ${ }^{7}$ Charge traps are due to physical defects (interstitial, vacancies, etc.) and chemical imperfections (interstitial or substitutional impurities) in the crystal lattice. These defects acting as traps for the implanted charges strongly modify dielectric properties and charge transport in the material. The energy and spatial distributions of these traps depend on the nature of the defects. A better understanding of these trapping/recombination mechanisms is needed to improve the physical models describing charge transport in space used dielectric materials. The cathodoluminescence (CL) technique is relevant to characterize the defects and impurities present in different materials, especially for the extraction of characteristic energies involved in trapping and recombination processes. In addition, CL measurement allows analyzing the evolution of chemical structure of the material along the irradiation process (aging phenomena).

In this paper, we focus on aluminum ceramic materials. A $\mathrm{CL}$ test bench has been developed to characterize these space materials. In the first part, we compare the nature and 
densities of the defects brought into evidence in AlN as a function of supplier and therefore processing route. In the second part, we investigate the influence of thermal annealing of AlN on CL spectra (an-AlN). Then, we will detail the different contributions present in alumina materials $\left(\mathrm{Al}_{2} \mathrm{O}_{3}\right)$. The effect of material temperature and cumulative radiation dose (aging) on ceramic materials (AlN, an-AlN, and $\mathrm{Al}_{2} \mathrm{O}_{3}$ ) will also be presented. This parametric study will enable us to identify the physical nature of the different emitted peaks (defects, recombination centers, etc.) and to assess the energy involved in the underlying processes.

\section{EXPERIMENTAL SETUP}

The irradiation test chamber MARCEL installed at ONERA (Toulouse, France) has been used in this study. It has been developed for the characterization of space used materials under electron irradiation. This facility has been amended to perform cathodoluminescence spectrometry. The experimental method developed in MARCEL for CL measurements is to implant incident electrons with calibrated energy and flux in order to collect photons emitted from the sample surface with a CL probe (parabolic mirror).

It is equipped with a $10 \mathrm{keV}$ (STAIB) electron gun and a non-contact Kelvin Probe (TREK model 341B). The axis of the gun is normal to the sample plane enabling possible light detection. The distance between the electron gun and the sample is about $50 \mathrm{~cm}$. A Faraday cup installed on the sample holder can measure the electron flux before tests. A pumping system allows performing experiments at vacuum of $1.10^{-6}$ mbar. The temperature of the sample holder (copper) can be controlled in the range $100-500 \mathrm{~K}$ allowing reproducing the temperature variations of materials on flight. Figure 1 provides a general schematic of the experimental system. A parabolic mirror (light collector) has been designed to enhance light collection. A hole with a diameter of $3 \mathrm{~mm}$ allows the path of the incident electrons to the sample. The focal point of the parabola is set on the specimen. A lens was attached to the probe to drive the luminescence toward the fiber inlet. A sealed feedthrough on the fiber allows the passage from the vacuum to the ambient atmosphere without loss of luminescence up to the UV-Vis-NIR spectrometer (StellarNet BLK-C-SR-50 model). The concave holographic grating spectrometers deliver high performance spectral analysis in the UV-Vis-NIR wavelength range covering 1.20-6.2 eV (200-1080 nm). The spectral resolution is determined by the grating and the slit width $(50 \mu \mathrm{m})$ and is typically $0.5 \mathrm{~nm}$. This grating is aberration corrected and has no mirrors to minimize stray light. The SpectraWiz software is used for data acquisition. Integrated times of 1-3 s were chosen to avoid noisy spectra. The obtained spectra have been deconvoluted into Gaussian sub-bands using commercially available software (Origin 9.1, OriginLab Co., Northampton, MA, USA).

Both surfaces of samples were metallized with semitransparent nanoscale layers of silver, which then remain grounded during irradiation. This process allows imposing a zero potential on the surface (constant incident energy). We demonstrated experimentally that the effect of this coating process on light intensity collected on the irradiated samples is very weak.

In this study, a continuous and focused beam (diameter $<3 \mathrm{~mm}$ ) was used with constant flux $\left(1 \mu \mathrm{Acm}^{-2}\right)$ and incident electrons energy at $10 \mathrm{keV}$. The penetration depth of incident electrons $(10 \mathrm{keV})$ has been estimated at $700 \mathrm{~nm}$ for these materials using the Casino software. ${ }^{8}$ Cathodoluminescence tests have been performed from $\sim 150 \mathrm{~K}$ to room temperature $(\sim 300 \mathrm{~K})$.

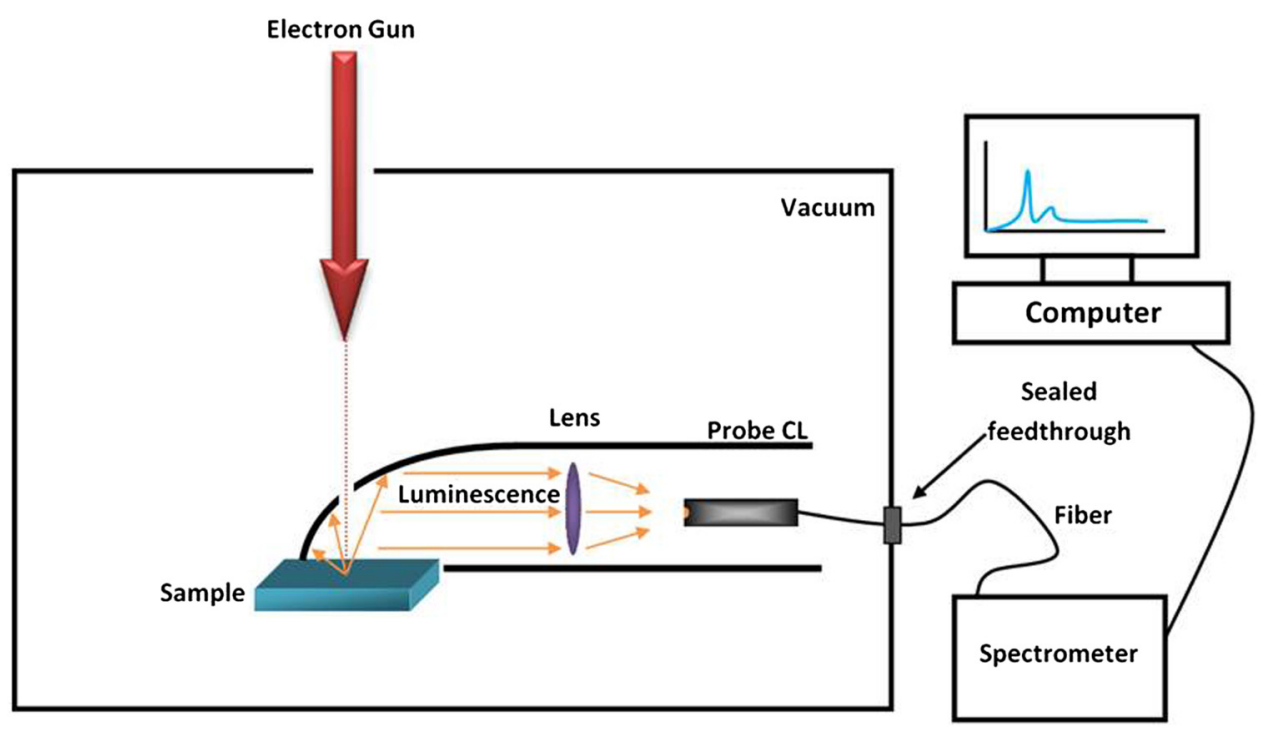

FIG. 1. Diagram of instrumentation used to characterize cathodoluminescence of samples irradiated with $10 \mathrm{keV}$ electrons in the MARCEL Facility. 
Measurements were carried out on different aluminum material samples: (1) AlN disks from supplier 1, (2) AlN disk from supplier 2, (3) annealed oxidized AlN (an-AlN) produced through the oxidation of AlN-supplier 2, and (4) aluminum oxide $\mathrm{Al}_{2} \mathrm{O}_{3}$.

\section{RESULTS}

\section{A. Influence of suppliers}

Emission spectra as a function of photon energy and wavelength are shown in Fig. 2(a) for two different AlN samples irradiated with $10 \mathrm{keV}$ electrons. We can notice that CL spectra are different as a function of supplier and therefore processing route. These spectra were fitted with least-squares methods for up to three Gaussian peaks [Figs. 2(b) and 2(c)]. The black curve shows the sum of the individual fitted peak profiles. We can see on both tested AlN (1-2), the same emission bands $(\sim 2.05 \mathrm{eV}, \sim 2.4 \mathrm{eV}$, and $\sim 3.5-3.7 \mathrm{eV})$ but with different ratios, which are attributed to bands of localized defect or "Deep Trap" (DT) states between the conduction and valence band edge (VBE). These spectra are widely dominated by the peak at $\sim 3.6 \mathrm{eV}$. We note that this peak is shifted with respect to AlN (2) by around $\sim 0.2 \mathrm{eV}$. Table I resumes parameters of the Gaussian components of CL spectra.

\section{B. Influence of annealing treatment}

In this part, the influence of a thermal annealing treatment on an-AlN (2) is detailed. Annealing of AlN substrate has
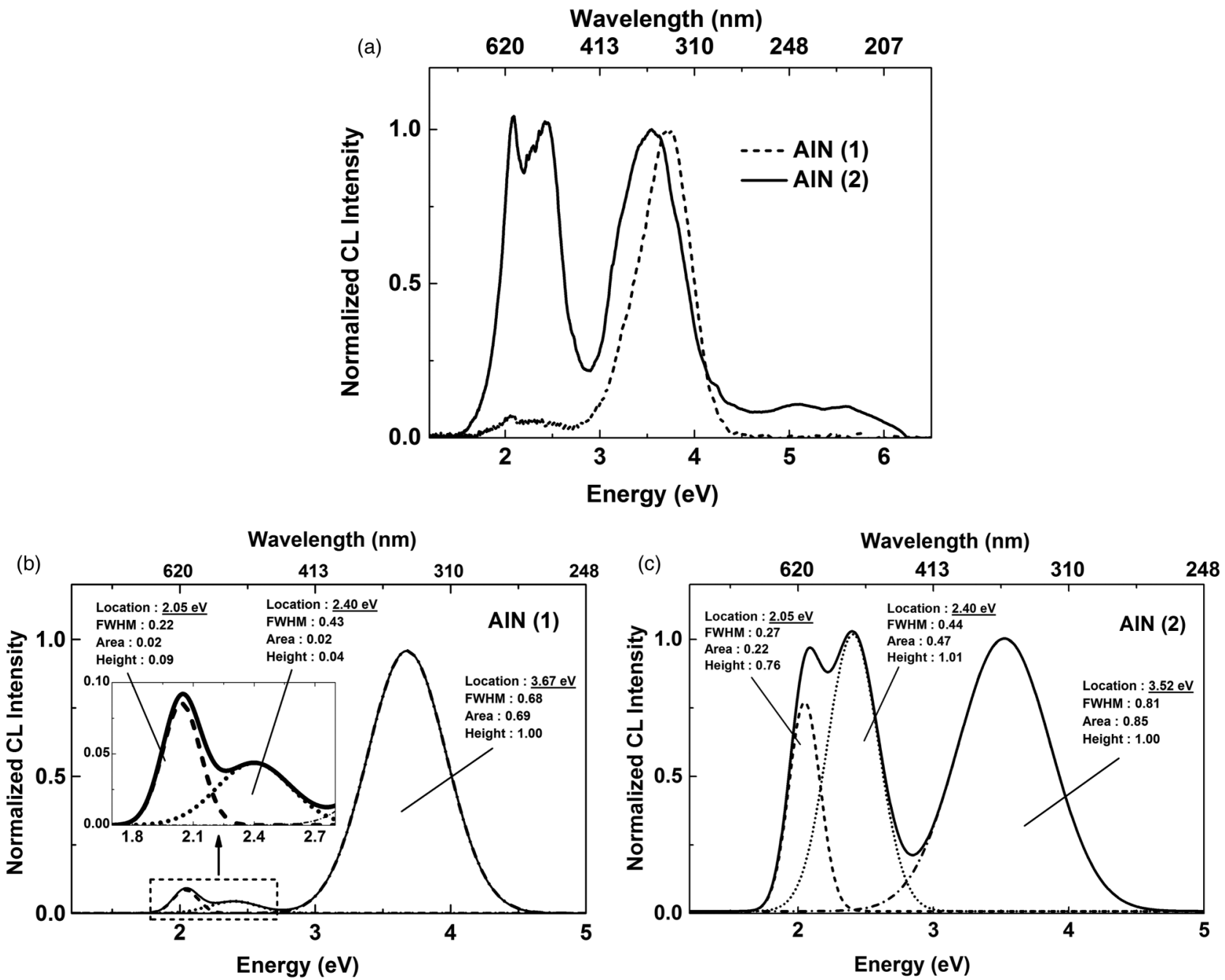

FIG. 2. (a) Cathodoluminescence emission spectra of AIN of two different suppliers (1-2). Curves are normalized from the intensity at $\sim 3.5$ eV emission band. (b) and (c) Gaussian component curves in the fit of AIN (1) and (2), respectively. The inset shows a zoom from 1.7 to $2.8 \mathrm{eV}$ of AIN (1). 
TABLE I. Parameters of the Gaussian components of $C L$ spectra decomposition (AIN).

\begin{tabular}{lcccc}
\hline \hline \multicolumn{5}{c}{ AIN } \\
\hline Peak $(\mathrm{eV})$ & Peak $(\mathrm{nm})$ & FWHM $(\mathrm{eV})$ & Defect & References \\
\hline 2.05 & 605 & 0.27 & $\mathrm{~V}_{\mathrm{Al}}$ & $12-16$ \\
2.40 & 514 & 0.44 & $\mathrm{~V}_{\mathrm{N}}$ & $16-18$ \\
3.52 & 352 & 0.81 & $\mathrm{O}_{\mathrm{N}}-\mathrm{V}_{\mathrm{A}} / \mathrm{O}_{\mathrm{N}}$ & $8-10$ \\
\hline \hline
\end{tabular}

been performed at $1273 \mathrm{~K}$ in air for more than $1 \mathrm{~h}$. Figure 3 compares spectra emitted by pristine AlN and annealed AlN. Considerable spectral changes occur in the energy region 1.5$6 \mathrm{eV}$. Thermal annealing dramatically enhances the CL intensity of each contribution $(\sim 2.40 \mathrm{eV}, \sim 3.52 \mathrm{eV}$, and the shoulder at $\sim 2.05 \mathrm{eV}$ ).

During annealing, the oxygen diffusing air into the AlN reacts with the material forming a new AlN oxide. These centers are therefore related to the oxygen atoms and will be detailed in Sec. IV. We can clearly see that an-AlN presents a slight shift toward high energy in comparison with AlN (see Tables I and II). A new band at $\sim 1.8 \mathrm{eV}$ is observed and corresponds to two additional peaks (A/B) (Fig. 4). Table II summarizes the different parameters of the Gaussian components of CL spectra decomposition of an-AlN.

To improve our understanding, a study on $\mathrm{Al}_{2} \mathrm{O}_{3}$ type materials was carried out. This study aims to compare these different peaks with those of AlN.

\section{CL Spectra of $\mathrm{Al}_{2} \mathrm{O}_{3}$}

CL spectrum of $\mathrm{Al}_{2} \mathrm{O}_{3}$ and its deconvolution are represented in Fig. 5. This spectrum shows five energetics transitions. Emission spectra of $\mathrm{Al}_{2} \mathrm{O}_{3}$ are dramatically different than $\mathrm{AlN}$ and an-AlN spectra. It can be seen that the $\mathrm{Al}_{2} \mathrm{O}_{3}$

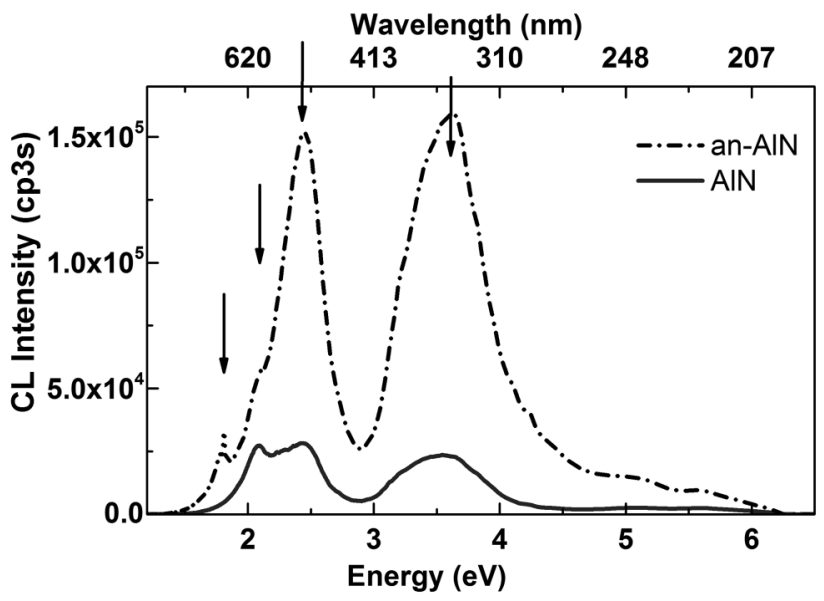

FIG. 3. Cathodoluminescence spectra for AIN (solid black) and an-AIN (short dash dot) under an excitation of $10 \mathrm{keV}-1 \mu \mathrm{A} \mathrm{cm}{ }^{-2}$ at $300 \mathrm{~K}$.
TABLE II. Parameters of the Gaussian components of CL spectra decomposition (an-AIN).

\begin{tabular}{lcccc}
\hline \hline \multicolumn{5}{c}{ an-AIN } \\
\hline Peak (eV) & Peak (nm) & FWHM (eV) & Defect & References \\
\hline 1.80 & 689 & 0.29 & $\mathrm{Ti}^{3+}$ & 19 \\
1.80 & 689 & 0.03 & $\mathrm{Cr}^{3+}$ & 19 \\
2.07 & 599 & 0.23 & $\mathrm{~V}_{\mathrm{Al}}$ & $12-16$ \\
2.43 & 510 & 0.39 & $\mathrm{~V}_{\mathrm{N}}$ & $16-18$ \\
3.57 & 347 & 0.83 & $\mathrm{O}_{\mathrm{N}}-\mathrm{V}_{\mathrm{Al}} / \mathrm{O}_{\mathrm{N}}$ & $8-10$ \\
\hline \hline
\end{tabular}

peak at around $\sim 4 \mathrm{eV}$ is asymmetric. Two relatively broad peaks at around $\sim 3.9 \mathrm{eV}$ and $\sim 4.1 \mathrm{eV}$ can be found by deconvolution from the CL spectrum of $\mathrm{Al}_{2} \mathrm{O}_{3}$ (Table III). A small peak is also present at around $\sim 2.4 \mathrm{eV}$ and two peaks are also present at $\sim 1.8 \mathrm{eV}$ (like an-AlN).

\section{Influence of temperature}

Cathodoluminescence (CL) as other luminescence phenomena depends strongly on temperature. All physical parameters controlling the optical and electrical phenomena (emission, absorption, gap, mobility of carriers, diffusion, intrinsic concentration, Fermi level, etc.) are indeed affected by temperature changes. A thorough study of $\mathrm{Al}_{2} \mathrm{O}_{3}, \mathrm{AlN}$ (supplier 2), and an-AlN at various temperatures was performed in order to get more information about electronic transitions within the bandgap. Figure 6 shows the evolution of the CL spectra of $\mathrm{Al}_{2} \mathrm{O}_{3}, \mathrm{AlN}$, and an-AlN as a function of temperature (150-300 K). The five contributions (at $\sim 1.72 \mathrm{eV}, \sim 1.8 \mathrm{eV}, \sim 2.4 \mathrm{eV}$, $\sim 3.8 \mathrm{eV}$, and $\sim 4.1 \mathrm{eV}$ ) of $\mathrm{Al}_{2} \mathrm{O}_{3}$ decrease with temperature. This drop is very important from $300 \mathrm{~K}$ to $200 \mathrm{~K}$. The intensities of the contributions at $\sim 2.05 \mathrm{eV}, \sim 2.4 \mathrm{eV}$, and $\sim 3.5 \mathrm{eV}$ in the AlN, respectively, decrease by a factor of 5,12 , and 8 when the temperature is divided by 2 ( $300 \mathrm{~K}$ to $150 \mathrm{~K})$. This decrease is less marked on the annealed AlN with a decrease by a factor by $1.4,7.1$, and 1.8 for the same peaks. The two contributions (an-AlN) at around $\sim 1.8 \mathrm{eV}$ are almost stable with the temperature. We clearly notice a raise of the contribution at about $\sim 5.6 \mathrm{eV}$ (AlN and an-AlN) with the lowering of the temperature. This peak $(\sim 5.6 \mathrm{eV})$ is 3 times greater than the peak at $3.4 \mathrm{eV}$ for $\mathrm{AlN}$ and 1.5 times for an-AlN at low temperature $(150 \mathrm{~K})$.

\section{E. Influence of irradiation time (dose)}

Three samples $\left[\mathrm{Al}_{2} \mathrm{O}_{3}\right.$, AlN (supplier 2), and an-AlN] have been irradiated for several minutes under high electron flux $\left(1 \mu \mathrm{A} \mathrm{cm}^{-2}\right)$ in order to study the evolution of defects/impurities as a function of ionizing dose. This process allows studying possible ageing effect due to electron irradiation used for the cathodoluminescence measurements.

Figure 7 shows the temporal evolution of CL intensity under prolonged irradiation for the different peaks. For these CL measurements, the dose rate is quite intense $\left(6.2 \times 10^{5} \mathrm{~Gy} \mathrm{~s}^{-1}\right)$. Cathodoluminescence measurements at 

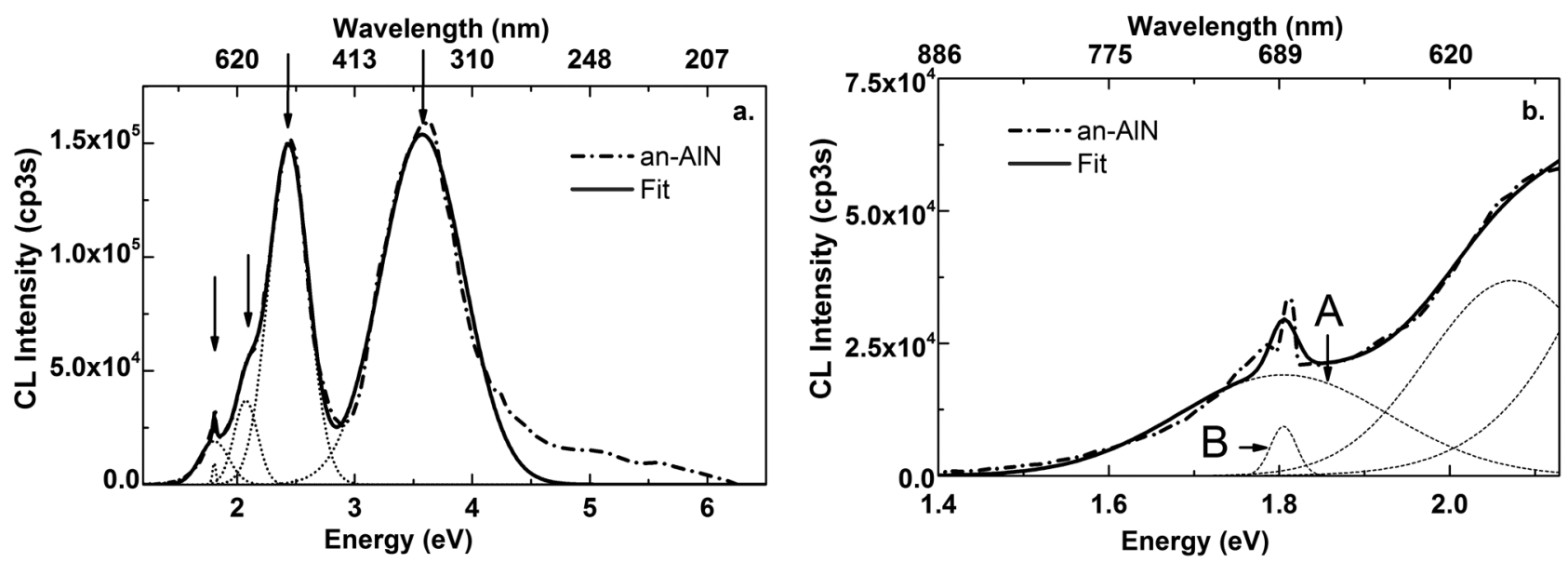

FIG. 4. Cathodoluminescence spectrum of an-AIN. Right graph shows a zoom (1.4 to $2.1 \mathrm{eV})$ of the component curves in the fits.

different electron dose ( 0 to $2.5 \times 10^{8}$ Gy) reveal a decrease in intensity of each contribution with increasing dose. The exception comes from the peak at $2.4 \mathrm{eV}$ for AlN, which increases for the first minutes of irradiation and then decreases.

\section{DISCUSSION}

As seen above, AlN presents 3 contributions at $\sim 3.5-3.7 \mathrm{eV}$, $\sim 2.4 \mathrm{eV}$, and $\sim 2.05 \mathrm{eV}$. The first peak at $\sim 3.5-3.7 \mathrm{eV}$ has been ascribed to the presence of oxygen, which is a commonly encountered impurity in the AlN ceramic. This transition is due to the recombination of donor-acceptor pairs. More precisely, the donor would be an electron trapped on an impurity of oxygen having replaced a nitrogen atom $\left(\mathrm{O}_{\mathrm{N}}\right.$ center) in the regular lattice. Mattila and Nieminen showed that substitutional oxygen $\left(\mathrm{O}_{\mathrm{N}}\right)$ was a deep center due to the wide bandgap. ${ }^{12}$ The acceptor was revealed to be a hole trapped on an $\mathrm{O}_{\mathrm{N}}-\mathrm{v}_{\mathrm{Al}}$ complex (with $\mathrm{O}_{\mathrm{N}}$ : oxygen on a regular $\mathrm{N}$ site and $\mathrm{v}_{\mathrm{Al}}$ : Al vacancy) created by irradiation (ionization processes). ${ }^{13}$ Recombination of the hole $\left(\mathrm{v}_{\mathrm{Al}}-\mathrm{O}_{\mathrm{N}}\right.$ centers) with the electron on $\mathrm{O}_{\mathrm{N}}$ centers results at $\sim 3.5 \mathrm{eV}$ luminescence. Many authors have associated the position of this peak with the oxygen concentration. ${ }^{9-11}$ As demonstrated by Slack et al. ${ }^{11}$ the increase of oxygen concentration leads to a shift of emission peak to lower energy (peak position of this band is $3.3 \mathrm{eV}$ when the oxygen concentration is $1.2 \times 10^{21} \mathrm{~cm}^{-3}$ and it
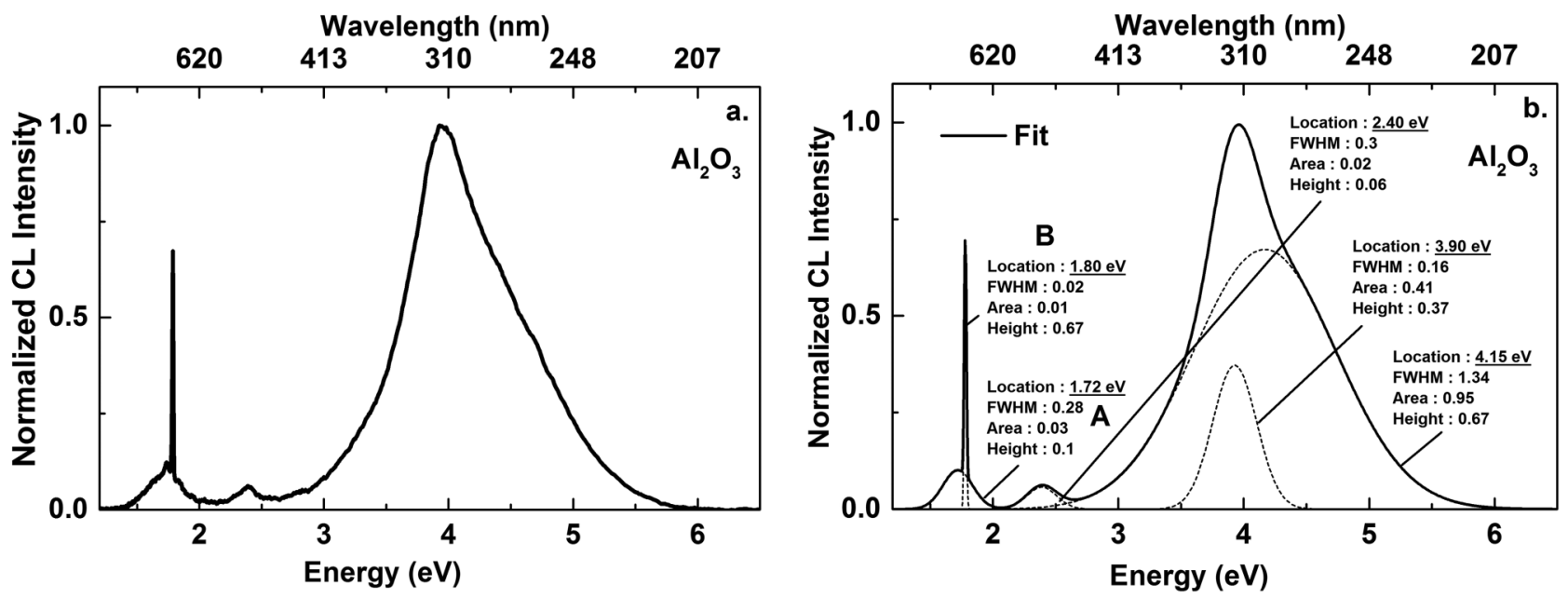

FIG. 5. CL spectra measured from the $\mathrm{Al}_{2} \mathrm{O}_{3}$ at $10 \mathrm{keV}-1 \mu \mathrm{Acm}{ }^{-2}$ at $300 \mathrm{~K}$ (a) and reconstruction of the $\mathrm{CL}$ spectrum in $\mathrm{Al}_{2} \mathrm{O}_{3}$ on the basis of five elementary components (b). 
TABLE III. Parameters of the Gaussian components of CL spectra decomposition $\left(\mathrm{Al}_{2} \mathrm{O}_{3}\right)$.

\begin{tabular}{lcccc}
\hline \hline \multicolumn{5}{c}{$\mathrm{Al}_{2} \mathbf{O}_{3}$} \\
\hline Peak (eV) & Peak (nm) & FWHM (eV) & Defect & References \\
\hline 1.72 & 721 & 0.28 & $\mathrm{Ti}^{3+}$ & 25 \\
1.80 & 689 & 0.02 & $\mathrm{Cr}^{3+}$ & 23,24 \\
2.40 & 516 & 0.3 & $\mathrm{~F}_{2}$ center or Al interst. & 23,24 \\
3.90 & 318 & 0.16 & $\mathrm{~F}^{+}$center & 20,21 \\
4.15 & 299 & 1.34 & $\mathrm{~F}_{\text {cat }}$ & 25 \\
\hline \hline
\end{tabular}

is at $3.8 \mathrm{eV}$, when the oxygen concentration is $5 \times 10^{19} \mathrm{~cm}^{-3}$ ). The peak at $2.4 \mathrm{eV}$ is difficult to interpret. Different studies disagree on the origin of this peak. It could be associated with the transition from the shallow donor $\left(\mathrm{v}_{\mathrm{N}}\right)$ to the deep acceptor. ${ }^{16,19,20}$ Different assumptions can be proposed to explain the origin of the emission band at $\sim 2.05 \mathrm{eV}^{14-16}$ Schulz et al. have theoretically predicted the existence of an energy level [Al vacancies $\left(\mathrm{v}_{\mathrm{Al}}\right)^{3-}$ ] at about $2.0 \mathrm{eV}$ above the Valence Band Edge (VBE). ${ }^{17}$ Negatively charged vacancies actually act as attractive centers for holes. During electron excitation, holes are generated in the VB (Valence Band) and transitions of electrons from the defect state $\left(\mathrm{v}_{\mathrm{Al}}\right)^{3-}$ to the VB become possible. ${ }^{14}$ The $\left(\mathrm{v}_{\mathrm{Al}}\right)^{3-}+\mathrm{h} \rightarrow\left(\mathrm{v}_{\mathrm{Al}}\right)^{2-}$ process results in an emission peak at $\sim 2.05 \mathrm{eV}$.

The large CL difference between both tested AlN is seen on the respective intensity of the peaks at $\sim 2.05 \mathrm{eV}$ and $\sim 2.4 \mathrm{eV}$. Indeed, they are less intense for AlN (1). Weinstein et al. showed that the peak intensity at about $2.1 \mathrm{eV}$ is weak in pure AlN without dopant. ${ }^{18}$ This observation is in line with Slack et al., who have reported that oxygen incorporation in AlN proceeds by the formation of $\mathrm{O}_{\mathrm{N}}$ accompanied by $\mathrm{v}_{\mathrm{Al}}$ for charge compensation. ${ }^{11}$ It can be said that AlN (1) has fewer defects in its crystallographic lattice (higher purity) and therefore fewer radiative transitions involving defects of nitrogen and aluminum vacancies.

Introduction of oxygen atoms into the lattice (by annealing treatment) generates an increase of the centers $\left(\mathrm{O}_{\mathrm{N}}, \mathrm{O}_{\mathrm{N}}-\mathrm{v}_{\mathrm{Al}}, \mathrm{v}_{\mathrm{Al}}\right.$, $\mathrm{v}_{\mathrm{N}}$ ) and thus a higher luminescence. The slight shift (see Tables I and II) can be related to the redistribution of vibrational states population of these defects. In addition, other impurities may be present in this material following insufficient purification. This is the case for the $1.8 \mathrm{eV}$ peaks present in an-AlN and $\mathrm{Al}_{2} \mathrm{O}_{3}$. These additional peaks are ascribed to the chromium (III) ions $\left(\mathrm{Cr}^{3+}\right)$ and titanium (III) ions $\left(\mathrm{Ti}^{3+}\right)$ substituting octahedral coordinated aluminum (III) ions $\left(\mathrm{Al}^{3+}\right)$, respectively. The impurity of chromium ions in the lattice is highlighted by one fine emission peak at around $1.8 \mathrm{eV}^{28}$ Very low concentration $(<5 \mathrm{ppm})$ of $\mathrm{Cr}^{3+}$ can cause intense emissions. ${ }^{29}$ The intense narrow CL peak "B" (red) is attributed to intra-center transition ${ }^{2} \mathrm{E} \rightarrow{ }^{4} \mathrm{~A}_{2}$ of $\mathrm{Cr}^{3+}$ defects. The broad red band "A" $(\sim 1.8 \mathrm{eV})$ observed in the spectra corresponds to the presence of $\mathrm{Ti}^{4+} / \mathrm{Ti}^{3+}$ impurities (two stable forms). ${ }^{21}$ Other divalent impurities $\left(\mathrm{Fe}^{2+}, \mathrm{Mg}^{2+}\right.$, or $\left.\mathrm{Ca}^{2+}\right)$ substituting to $\mathrm{Al}^{3+}$ may also be present. The annealing of AlN under an oxidizing atmosphere (an-AlN) caused the diffusion of these ions to the surface of the material inducing then an increase of the luminescence peak.

In $\mathrm{Al}_{2} \mathrm{O}_{3}$, the peak at $\sim 3.9 \mathrm{eV}$ is assigned to the center $\mathrm{F}^{+}$, which is an oxygen vacancy trapping one electron. ${ }^{22,23}$ No signal related to $\mathrm{F}$ centers (an oxygen vacancy occupied by two electrons) emitting at $\sim 3.0 \mathrm{eV}$ was detected. The absence of this peak can come either from material's thermochemical history during the elaboration (reducing atmosphere, heating treatments, etc.) ${ }^{22,24}$ or very high electron flux (the intensity ratio of $\mathrm{F}^{+} / \mathrm{F}$ increases). ${ }^{23} \mathrm{~A}$ number of papers report a weaker luminescence in the $2.4 \mathrm{eV}$ peaks, which are attributed to defects in the anion sublattice $\left(\mathrm{F}_{2}\right.$ centers) or to interstitial aluminum atoms. ${ }^{25,26}$ The higher energy emission band at $\sim 4.1 \mathrm{eV}$ is characteristic of the divalent impurities $\left(\mathrm{Ca}^{2+}, \mathrm{Mg}^{2+}\right.$, or $\mathrm{Fe}^{2+}$ ) denoted $\mathrm{F}_{\text {cat. }}{ }^{27}$ Ghamnia et al. ${ }^{27}$ have detailed the overall mechanisms related to emissions,

$$
\begin{gathered}
\mathrm{Cr}^{3+}+\operatorname{excitation}\left(\mathrm{e}^{-}\right) \rightarrow\left(\mathrm{Cr}^{3+}\right) * \rightarrow \mathrm{Cr}^{3+}+\mathbf{h} \boldsymbol{v}(\sim \mathbf{1 . 8} \mathrm{eV}) \\
\mathrm{Ti}^{3+}+\operatorname{excitation}\left(\mathrm{e}^{-}\right) \rightarrow\left(\mathrm{Ti}^{3+}\right) * \rightarrow \mathrm{Ti}^{3+}+\mathbf{h} v(\sim \mathbf{1 . 7 2} \mathrm{eV}) \\
\mathrm{F}^{+}+\operatorname{excitation}\left(\mathrm{e}^{-}\right) \rightarrow\left(\mathrm{F}^{+}\right) * \rightarrow \mathrm{F}^{+}+\mathbf{h} \boldsymbol{v}(\sim \mathbf{3 . 9 e V}) \\
\mathrm{F}_{\text {cat }}+\operatorname{excitation}\left(\mathrm{e}^{-}\right) \rightarrow\left(\mathrm{F}_{\mathrm{cat}}\right) * \rightarrow \mathrm{F}_{\mathrm{cat}}+\mathbf{h} \boldsymbol{v}(\sim \mathbf{4 . 1 e V})
\end{gathered}
$$

The asterisk denotes the excited state.
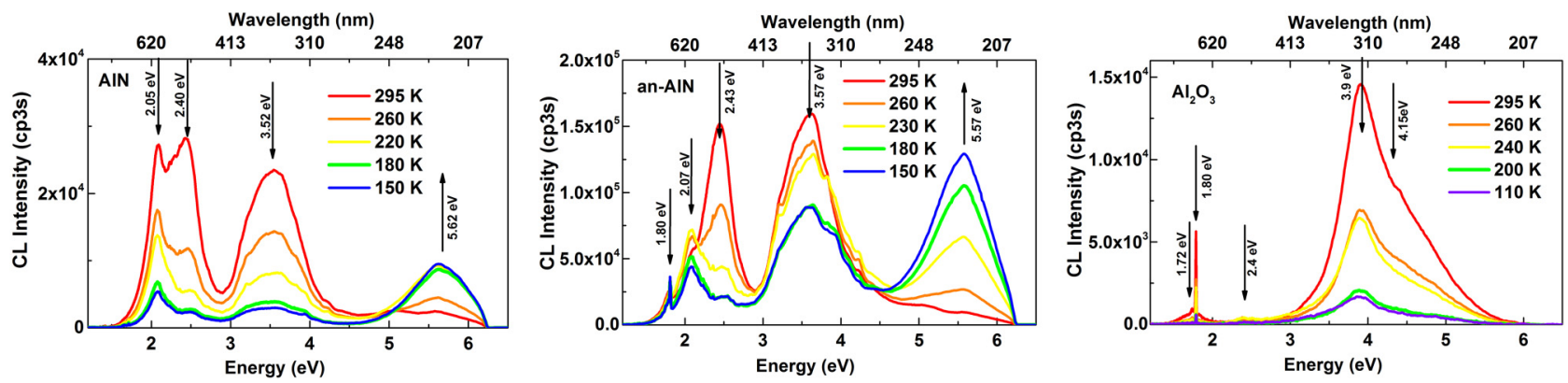

FIG. 6. Evolution of the different $\mathrm{CL}$ emission spectra as a function of temperature ( $300 \mathrm{~K}$ to $150 \mathrm{~K})$. 

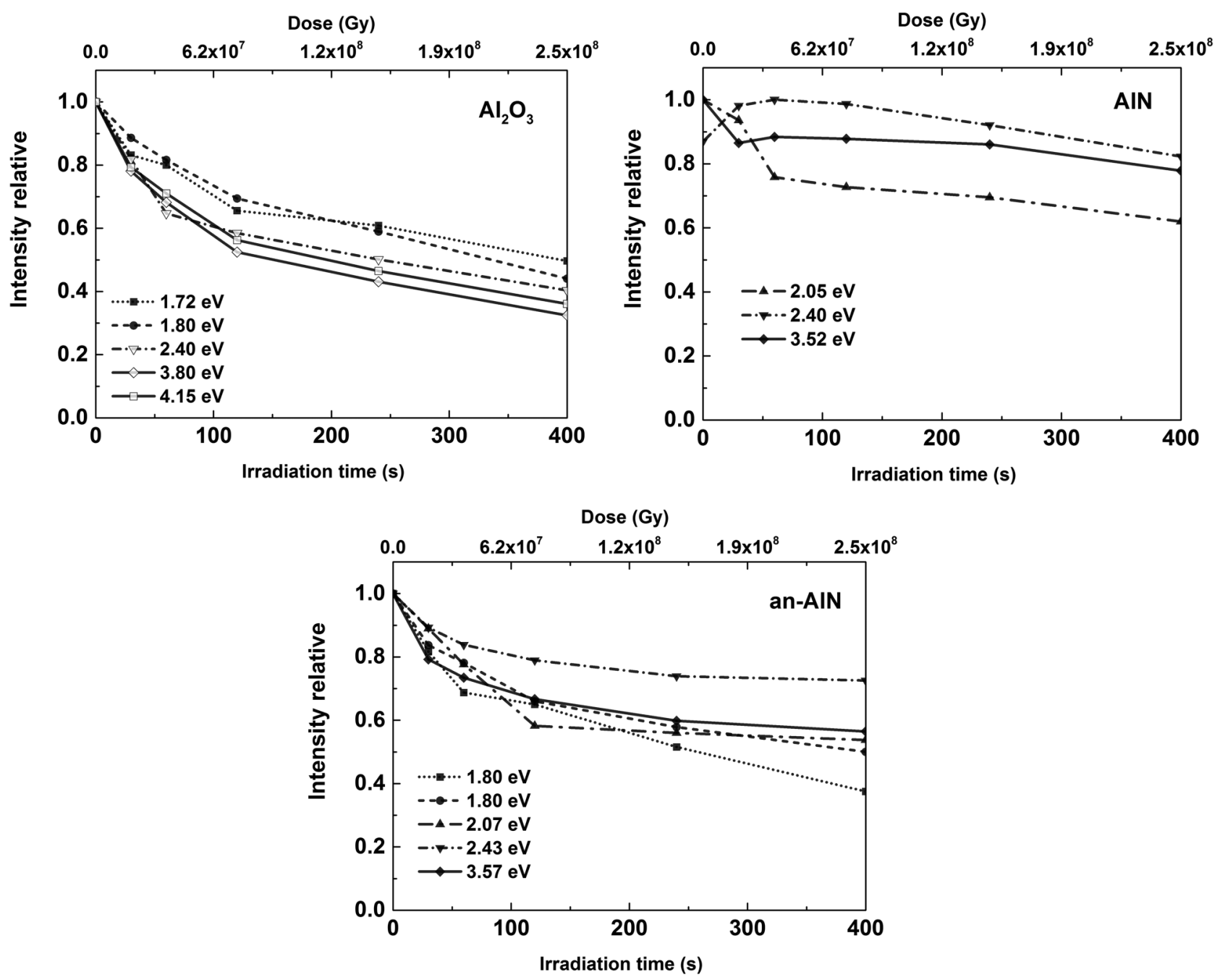

FIG. 7. Evolution of cathodoluminescence of $\mathrm{Al}_{2} \mathrm{O}_{3}$, $\mathrm{AIN}$, and an-AIN as a function of irradiation time under bombardment of $10 \mathrm{keV}$ at $1 \mu \mathrm{A} \mathrm{cm}{ }^{-2}$ and at $300 \mathrm{~K}$.

In general, all $\mathrm{CL}$ spectra of $\mathrm{AlN}$, an- $\mathrm{AlN}$, and $\mathrm{Al}_{2} \mathrm{O}_{3}$ decrease with temperature $(300 \mathrm{~K}$ to $150 \mathrm{~K})$, except the peak at $\sim 5.2 \mathrm{eV}$ for AlN and an-AlN. No current articles mention its origin. This energy transition could correspond to a recombination (electron-hole) between defects close to the valence and conduction band (Shallow Trap "ST") with $\mathrm{E}_{\mathrm{g}} \sim$ $6.2 \mathrm{eV}$. The absence of a similar peak in the case of $\mathrm{Al}_{2} \mathrm{O}_{3}$ could be explained by a higher gap energy $(\sim 9 \mathrm{eV}) .^{6}$ This energy transition would be in the Far-UV. It is not surprising not to observe this peak for $\mathrm{Al}_{2} \mathrm{O}_{3}$ since our spectral range extends from 1.2 to $6.2 \mathrm{eV}$ (if the process exists). A simple model is presented in Fig. 8 to explain qualitatively the temperature dependence of the observed luminescence spectra based on a well-known model accepted in this field (Fig. 8). ${ }^{30}$ Electronic bombardment leads to the creation of electronhole pairs by ionization processes (1). These different charges (electron-hole) will migrate (2) in their respective bands (conduction or valence band) before being trapped by shallow and/or deep traps (3). These charges can be transferred into neighboring traps "inter-trap transfer" (4) by thermal activation (hopping mechanisms) and thus contribute to intraband recombination processes (5). Interband transitions $(\sim 5.6 \mathrm{eV})$ may also be present (6). At low temperatures, intraband transitions are less important than at higher temperatures (less hopping mechanism by assisted phonon). The peak at $\sim 5.6 \mathrm{eV}$ corresponding to interband transitions is therefore favored (less interaction with phonons). As temperature increases, intraband recombination processes increase and interband processes decrease. This observation could be due to an increase in inter-trap transfer (with temperature), thus leading to an increase in intraband recombination mechanisms. Lowering the contribution to $5.6 \mathrm{eV}$ with temperature 


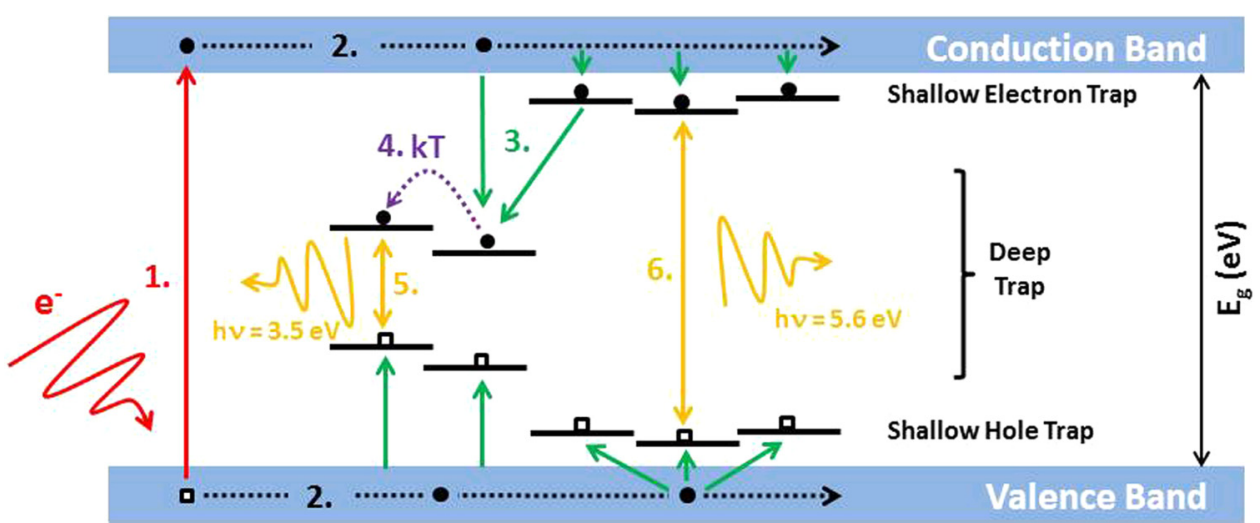

FIG. 8. Qualitative model of the processes that cause cathodoluminescence in AIN. 1. Ionization; 2. Diffusion; 3. Trapping; 4. Detraping "inter-trap transfer"; 5 and 6. Recombination (photon emission).

could be due to energy relaxation mechanisms (non-radiative) between shallow to deep traps (ST to DT), thus reducing the number of charge carriers involved.

Cathodoluminescence measurements at different electron doses $\left(0\right.$ to $\left.2.5 \times 10^{8} \mathrm{~Gy}\right)$ reveal a decrease in intensity of each contribution with increasing dose (Fig. 7). The exception comes from the peak at $2.4 \mathrm{eV}$ for AlN which increases for the first minutes of irradiation and then decreases. This peak corresponds to nitrogen vacancies as previously explained. This initial increase could be due to the creation of nitrogen vacancies under the electron beam [by degassing processes $\left.\left(\mathrm{N}_{2}\right)\right]$. ${ }^{31}$ We can see that in the case of an-AlN, no increase of this peak is present. This observation is interesting and shows that the oxygen present in the material has diffused on the surface by substituting the nitrogen sites. Except for this peak $(\sim 2.4 \mathrm{eV})$, we can see that decay kinetics is quite similar for the different contributions. The decrease of CL intensity with dose may be related to structural evolution of the irradiated specimens. New defect centers could be created in the material promoting non-radiative trapping or recombination processes. This decrease would be linked to the competition between these new centers and those present in the initial state. We can also assume that under high radiation flux, the charges generated by ionization rapidly fill the different traps present in the gap band. This limits the number of available states (saturation) in which the charges can decay and thus decrease the luminescence efficiency. Dark spots have also been observed after exposure. This color change could come from a change in the chemical structure on the surface material. Using empirical relationships, ${ }^{32,33}$ we were able to evaluate the temperature change of the irradiated zone during electron irradiation. The thermal gradients for $\mathrm{Al}_{2} \mathrm{O}_{3}$ and $\mathrm{AlN}$ are 0.08 and $0.008 \mathrm{~K} / \mathrm{s}$, respectively (for thermal conductivities of $\lambda_{\mathrm{Al} 2 \mathrm{O} 3} \sim 30 \mathrm{~W} \mathrm{~m}^{-1} \mathrm{~K}^{-1}$ and $\lambda_{\mathrm{AlN}} \sim 300 \mathrm{~W} \mathrm{~m}^{-1} \mathrm{~K}^{-1}$ ). Thermal conductivity values may vary depending on the purity of the material and sintering processes (microstructure). The intensity variations with dose are not due to localized heating effects (melting, thermal decomposition, etc.) because their thermal conductivity is high.

\section{CONCLUSION}

In conclusion, a comprehensive description of luminescence properties of different aluminum based compounds has been performed. We have shown that the defects present in a material depend essentially on the processing route. CL is a powerful technique for the first approach of the purity of a material. We were able to show that the majority of defects in this type of material were essentially related to oxygen impurities or vacancy sites $\left(\mathrm{v}_{\mathrm{Al}}\right.$ and $\left.\mathrm{v}_{\mathrm{N}}\right)$. The heat treatment under oxidizing atmosphere of AlN sample generates an increase of surface defects. We have been able to relate common defects $(\sim 1.8 \mathrm{eV})$ between $\mathrm{AlN}$ and $\mathrm{Al}_{2} \mathrm{O}_{3}$ corresponding to $\mathrm{Cr}^{3+}, \mathrm{Ti}^{3+}$, and $\mathrm{Ti}^{4+}$ ions. Additional tests could be interesting to evaluate the effect of these defects on the surface conductivity. The temperature tests showed that the CL spectra decreased mainly with lowering temperature except a peak at $\sim 5.2 \mathrm{eV}$. This additional contribution attributed to interband recombination mechanisms becomes more and more prominent when temperature decreases. This behavior has been described through a qualitative model. The different contributions showed a decrease with respect to the dose received apart from $\sim 2.4 \mathrm{eV}$, which has been attributed to degassing processes (creation of nitrogen vacancies). This trend has been associated with the creation of new centers that would promote non-radiative transitions or saturation of trap levels.

\section{ACKNOWLEDGMENTS}

This work was supported by the Centre National d'Etudes Spatiales (CNES) throughout the R\&T programs. The authors thank the development team for CASINO (monte CArlo SImulation of electroN trajectory in sOlids) and for making available their software to the scientific community. 


\section{REFERENCES}

${ }^{1}$ C.-L. Tsai, H.-H. Liu, J.-W. Chen, C.-P. Lu, K. Ikenaga, T. Tabuchi, K. Matsumoto, and Y.-K. Fu, Solid-State Electron. 138, 84 (2017).

${ }^{2}$ F. Miyashiro, N. Iwase, A. Tsuge, F. Ueno, M. Nakahashi, and T. Takahashi, IEEE Trans. Comp. Hybrids Manuf. Technol. 13, 313 (1990).

${ }^{3}$ Y. Taniyasu, M. Kasu, and T. Makimoto, NTT Tech. Rev. 4, 54 (2006).

${ }^{4}$ T. Oto, R. G. Banal, K. Kataoka, M. Funato, and Y. Kawakami, Nat. Photonics 4, 767 (2010).

${ }^{\mathbf{5}}$ R. G. Banal, M. Funato, and Y. Kawakami, Appl. Phys. Lett. 92, 241905 (2008).

${ }^{6} \mathrm{P}$. W. Levy, Phys. Rev. 123, 1226 (1961).

${ }^{7}$ R. Hanna, T. Paulmier, P. Molinie, M. Belhaj, B. Dirassen, D. Payan, and N. Balcon, J. Appl. Phys. 115, 033713 (2014).

${ }^{8}$ P. Hovington, D. Drouin, and R. Gauvin, Scanning 19, 1 (1997).

${ }^{9}$ S. Pačesová and L. Jastrabík, Czechoslov. J. Phys. B 29, 913 (1979).

${ }^{10}$ R. A. Youngman and J. H. Harris, J. Am. Ceram. Soc. 73, 3238 (1990).

${ }^{1}$ G. A. Slack, L. J. Schowalter, D. Morelli, and J. A. Freitas, J. Cryst. Growth 246, 287 (2002).

${ }^{12}$ T. Mattila and R. M. Nieminen, Phys. Rev. B 54, 16676 (1996).

${ }^{13}$ B. Berzina, J. Nanophotonics 3, 031950 (2009).

${ }^{14}$ D. M. Spiridonov, I. A. Weinstein, A. S. Vokhmintsev, and A. R. Beketov, Bull. Russ. Acad. Sci. Phys. 79, 211 (2015).

${ }^{15} \mathrm{~L}$. Shen, N. Wang, and X. Xiao, Mater. Lett. 94, 150 (2013).

${ }^{16}$ I. A. Aleksandrov, V. G. Mansurov, V. F. Plyusnin, and K. S. Zhuravlev, Phys. Status Solidi C 12, 353 (2015)

${ }^{17}$ T. Schulz, M. Albrecht, K. Irmscher, C. Hartmann, J. Wollweber, and R. Fornari, Phys. Status Solidi B 248, 1513 (2011).
${ }^{18}$ I. A. Weinstein, A. S. Vokhmintsev, and D. M. Spiridonov, Diamond Relat. Mater. 25, 59 (2012).

${ }^{19}$ Y. Lan, X. Chen, Y. Cao, Y. Xu, L. Xun, T. Xu, and J. Liang, J. Cryst. Growth 207, 247 (1999).

${ }^{20}$ N. Nepal, M. L. Nakarmi, H. U. Jang, J. Y. Lin, and H. X. Jiang, Appl. Phys. Lett. 89, 192111 (2006)

${ }^{21}$ R. C. Powell, G. E. Venikouas, L. Xi, J. K. Tyminski, and M. R. Kokta, J. Chem. Phys. 84, 662 (1986).

${ }^{22} \mathrm{M}$. Ghamnia and C. Jardin, Philos. Mag. B 76, 875 (1997).

${ }^{23} \mathrm{~K}$. Furumoto, T. Tanabe, N. Yamamoto, T. Daio, S. Matsumura, and K. Yasuda, Mater. Trans. 54, 854 (2013).

${ }^{24}$ B. D. Evans and L. S. Cain, Radiat. Eff. Defects Solids 134, 329 (1995).

${ }^{25}$ A. S. Vokhmintsev, I. A. Weinstein, and V. S. Kortov, Radiat. Meas. 56, 228 (2013).

${ }^{26}$ M. J. Springis and J. A. Valbis, Phys. Status Solidi B 123, 335 (1984).

${ }^{27} \mathrm{M}$. Ghamnia, C. Jardin, and M. Bouslama, J. Electron Spectrosc. Relat. Phenomena 133, 55 (2003).

${ }^{28} \mathrm{~K}$. Guerch, J. Dekany, J. R. Dennison, J. Christensen, T. Paulmier, S. Guillemet-Fritsch, and P. Lenormand, J. Phys. D 50, 295302 (2017).

${ }^{29} \mathrm{P}$. Jonnard, C. Bonnelle, G. Blaise, G. Rémond, and C. Roques-Carmes, J. Appl. Phys. 88, 6413 (2000).

${ }^{30}$ A. E. Jensen and J. R. Dennison, IEEE Trans. Plasma Sci. 43, 2925 (2015).

${ }^{31}$ T. Nöbauer, K. Buczak, A. Angerer, S. Putz, G. Steinhauser, J. Akbarzadeh, H. Peterlik, J. Majer, J. Schmiedmayer, and M. Trupke, e-print arXiv:1309.0453 (Cond-Mat, Physics:Quant-Ph) (2013).

${ }^{32}$ L. Reimer, Scanning Electron Microscopy: Physics of Image Formation and Microanalysis (Springer-Verlag, Berlin Heidelberg, 1998).

${ }^{33}$ S. J. B. REED, Electron Microprobe Analysis and Scanning Microscopy in Geology (Cambridge University Press, 2005). 